\title{
INFRANGÍVEL E DESMESURA: DUAS POTÊNCIAS DA PAISAGEM
}

Ana Carla de Brito

\section{RESUMO}

Este trabalho trata de algumas obras de Thiago Rocha Pitta procurando contemplar dois aspectos: o fascínio frente à paisagem como desastre; e a interrogação da visibilidade de elementos incorpóreos. Comparece como articulação teórica Immanuel Kant, que permite refletir sobre a atração pelo que é temível e imensurável; Maurice Blanchot, cujas reflexões autorizam a compreensão de certas nuances relativas ao processo de criação; e François Cheng, que permite pensar a fugacidade dos vapores através do conceito de devir recíproco identificado com a pintura de paisagem chinesa.

Palavras Chave

Thiago Rocha Pitta, paisagem, Arte Contemporânea.

\begin{abstract}
This paper deals with some works by Thiago Rocha Pitta, trying to regard two aspects: the fascination in front of the landscape as a disaster; and the interrogation about the visibility of intangible items. Immanuel Kant is present as a theoretical articulator who allows a reflection about the attraction of what is fearful and immeasurable; Maurice Blanchot, whose reflections authorize the understanding of some nuances concerning the creation process; and François Cheng, who suggests the fugacity of vapors through the concept of reciprocal transformation identified with the Chinese landscape painting.
\end{abstract}

Key words

Thiago Rocha Pitta, landscape, Contemporary Art.

\section{A desmesura do desastre}

Thiago Rocha Pitta (Tiradentes, 1980) realizou em 2002 um trabalho a que denominou Homenagem a JMW Turner, e foi exposto no mesmo ano na mostra individual Homenage to William Turner realizada no Espaço cultural Sergio Porto, no Rio de Janeiro. De forma semelhante a este pintor inglês que viveu no século XIX, o 
artista se interessa pelas forças da natureza, ainda que o contato com ela seja sempre imiscuído de cultura, manejo humano, conforme diz em uma entrevista: Eu trabalho do lado do cozido, não do $\mathrm{cru}^{1}$.

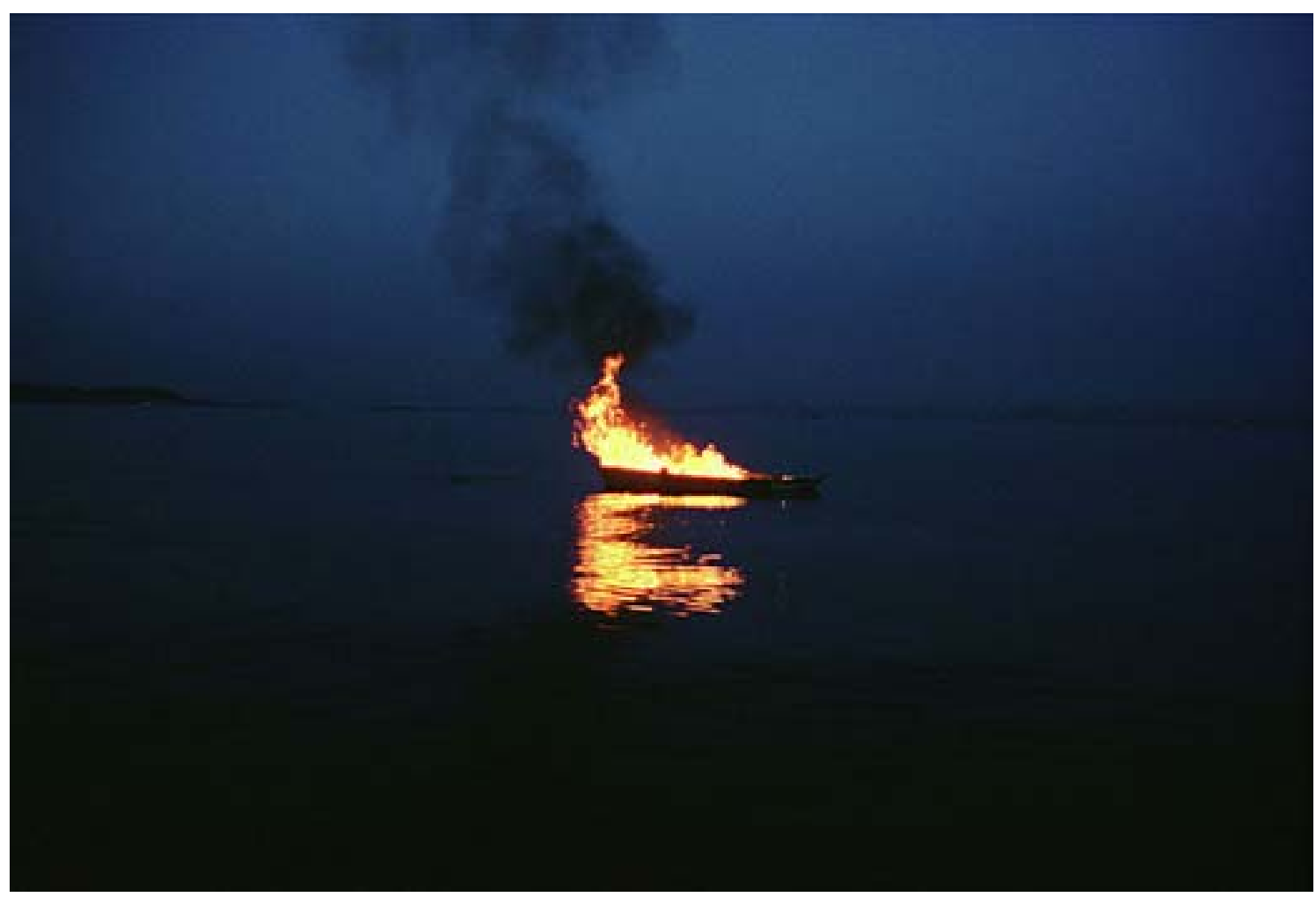

Thiago Rocha Pitta. Homenagem a JMW Turner. Still de vídeo.

Filme 16mm digitalizado, 17 minutos, 2002.

No referido trabalho, um barco simples aparece em chamas durante os dezessete minutos do vídeo, feito em filme de 16 milímetros, na ilha do fundão, na cidade do Rio de Janeiro. Ouve-se constantemente o som das ondas e pode-se ver o pequeno barco aproximadamente no meio da tela, em um horizonte oscilante devido ao movimento do barco do cinegrafista. A imagem traz em simetria, céu e mar, a chama que se desvanece no ar e seu reflexo dourado na água. O azul escuro profundo do céu e do mar vai se obscurecendo até mergulhar no breu noturno. Durante alguns minutos a imagem do barco em chamas parece se distanciar e as labaredas, diminuírem, até quase se extinguirem. Então, aproximadamente aos seis minutos e trinta segundos, o fogo retoma seu vigor, e, à medida que o barco do

\footnotetext{
1 Entrevista publicada em quatro de novembro de 2009. Disponível em: http://www.youtube.com/watch?v=cIlwrPbUuAg
} 
cinegrafista se aproxima mais e mais, as chamas crescem, dançam no ar e reluzem no seu reflexo aquoso, fluídas e rítmicas. Toma conta da tela uma imagem informe e incandescente. Grandes labaredas douradas se insinuam em meio à escuridão.

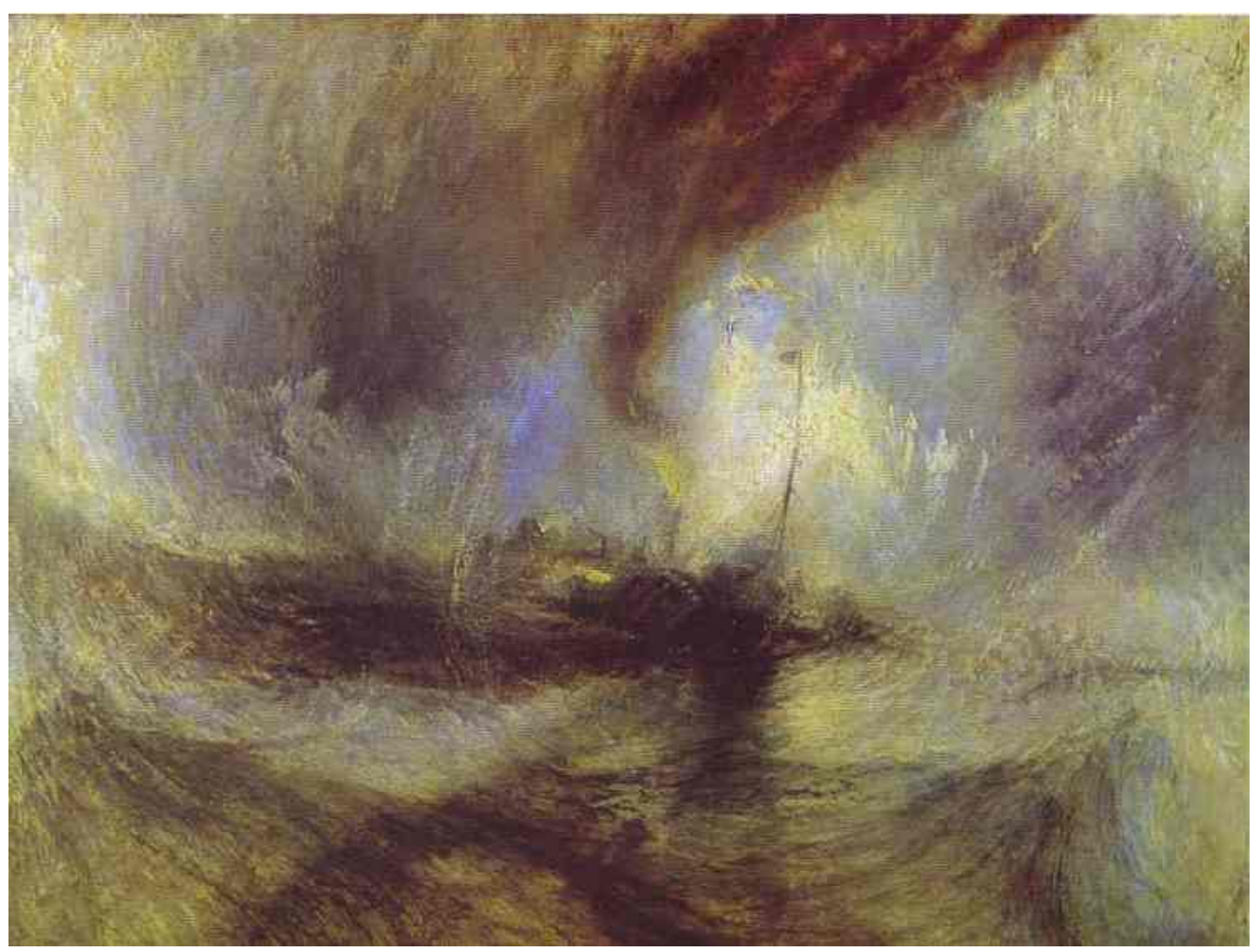

William Turner. Tempestade de neve - navio à entrada do Porto a fazer sinais em fundo baixo e guiando-se pelo prumo. O autor estava neste temporal na noite em que o Ariel zarpou de Harwich. 1842. Óleo sobre tela, $91,5 \times 122 \mathrm{~cm}$. Londres, The Tate Gallery.

Nas paisagens de Turner há também embate. Em seus quadros, a natureza se ergue arrasadora sobre a debilidade humana, já nas pinturas de sua maturidade a pintura inteira é tempestade e assolação, como pode ser visto em Tempestade de Neve de 1842, em que Turner se ocupa da atmosfera, dá opacidade a ela, como se quisesse nos transportar para aquele momento e estivéssemos no barco ao lado sentindo nosso rosto açoitado pelo mesmo vento intempestivo que maltrata o navio retratado. Entretanto, a imagem do navio incendiado em Homenagem a JMW Turner nos remete à obra Sepultura Marítima, do pintor inglês. Nessa pintura a dramaticidade é conferida pela proximidade dos dois navios em chamas e pelo alto contraste entre luz e sombra que é propiciada pela atmosfera turva e a obscuridade que recobre as embarcações, contrapostas ao brilho do fogo refletido no mar. Porém, a pintura não é iluminada apenas pelas chamas incendiárias, pois 
vemos em várias áreas incidir uma luz difusa, o que poderia indicar a possibilidade de a cena ter sido retratada como se passasse durante o dia. No trabalho de Thiago Rocha Pitta, por outro lado, o ambiente fica cada vez mais escuro, de maneira que além de se configurar como força destruidora, o fogo comparece como elemento central, tomando aspecto hipnotizante, como uma dança calma do desastre.

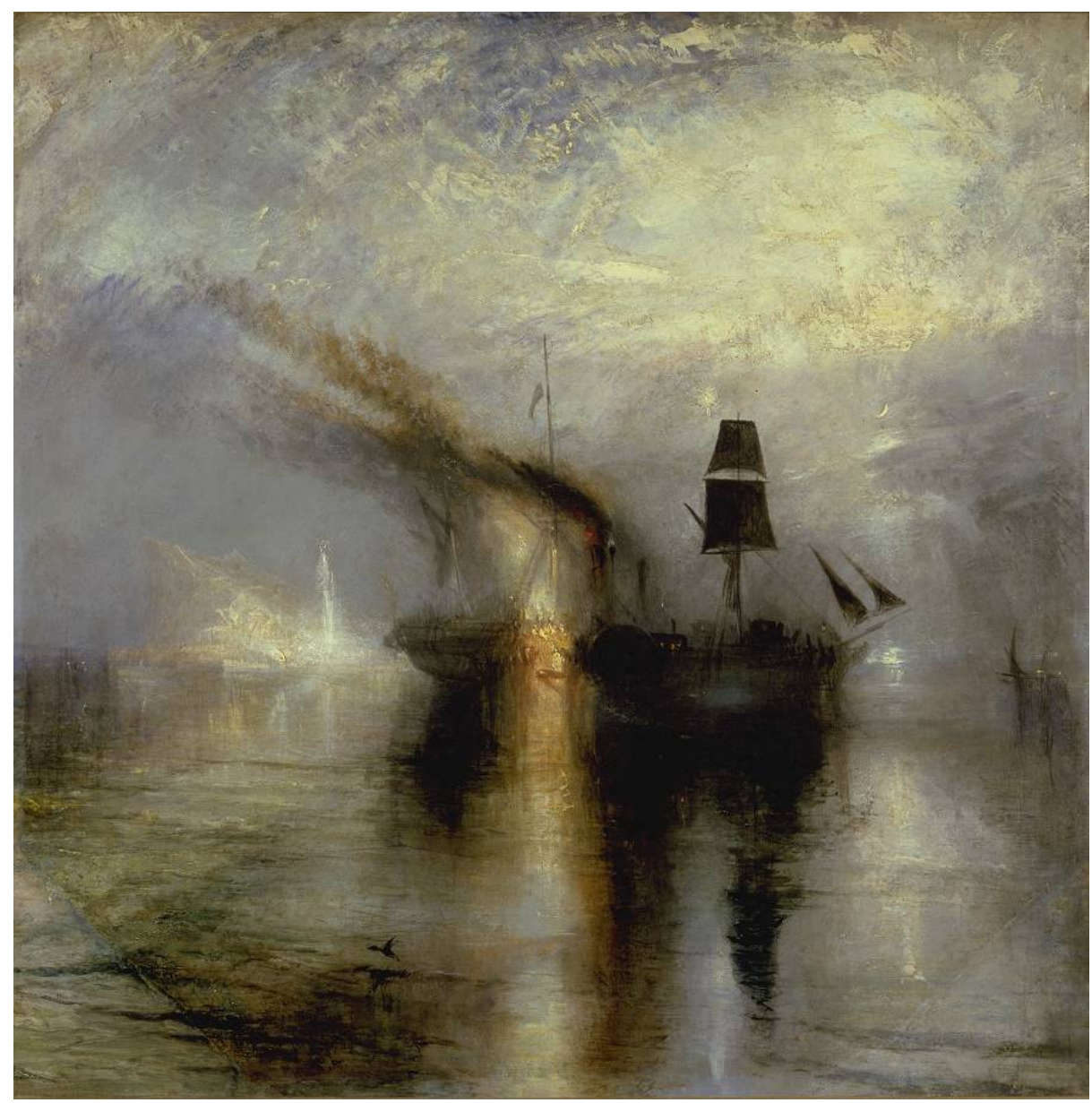

Turner. Paz - Sepultura Marítima. 1842.

Óleo sobre tela, 87 x 86,5 cm. Londres, The Tate Gallery.

O desastre sem medida prestes a se abater contra as pequenas figuras humanas, ou envolvendo em furor as embarcações nas pinturas de Turner, demonstram não apenas a desmedida da natureza, como também do artista que é atraído pelo terrificante e para ele se volta, como que se debruçando sobre o abismo, hipnotizado e incauto, ainda que assombrado. Essas são, pois, as características desse movimento que agita o espírito diante da desmesura do desastre, e que Kant se ocupa em explicar: Trata-se de um movimento de rápida alternância entre atração e repulsão. A imaginação é atraída pelo terrificante como 
um abismo, um excesso onde esta faculdade teme se perder. Em seguida, o objeto provoca o distanciamento, na medida em que é atemorizante e a imaginação não pode abarcá-lo, causando a sensação de melancolia e impotência ou de pequenez diante do que se observa. No entanto, apesar de tais sentimentos negativos suscitarem o espanto que naturalmente impulsiona a um afastamento, produz, paradoxalmente, um prazer negativo. Para Kant haveria ainda um movimento final de atração, que consistiria na superação da imaginação pela razão, visto que esta faculdade seria capaz de apreender conceitualmente o que é visto e assim apaziguar a angústia inicial ${ }^{2}$. Em Homenagem a JMW Turner ocorre de semelhante modo. O artista se aproxima cada vez mais do barco em chamas, e, à medida que elas tomam grande proporção, a atração que exercem cresce, e também a sensação de perigo pela proximidade a uma força à qual dificilmente se poderia opor resistência. Poderíamos então nos perguntar o porquê da atração pelo espantoso e temível. Que potência criadora vela esse gesto de destruição de que dispôs Thiago Rocha Pitta?

O escritor francês Maurice Blanchot, ao teorizar a respeito da criação literária, versa quanto à relação aferida por alguns escritores entre a morte e a exigência que a criação artística Ihes trazia. Diversas experiências são expostas ${ }^{3}$, de Valéry a Rilke, passando por Kafka, Dostoievsky e Malarmé, em que as agruras suscitadas pela lida com a escrita rondam a questão da morte, seja no sentido de finitude da vida ou na de apagamento do escritor durante o processo de criação. No primeiro caso, tem-se em Kafka a concepção de que seria necessário encontrar contentamento na morte para possibilitar a escrita; e em Dostoievsky, o personagem Kirilov que intenta encontrar no suicídio a morte supremamente humana. Já no segundo caso, enquadra-se Mallarmé, com a concepção de morte enquanto potência negativa interior, relativa mais ao espírito do que ao gesto de dar cabo da vida no corpo; e Rilke, segundo o qual a apreensão da morte deve ser uma tentativa terrena, ainda que tal coisa não seja possível, mas se refira ao que sempre escapa.

De que maneira essas considerações a respeito da literatura nos ajudam a pensar sobre a potência criativa da destruição e o fascínio do desastre? À semelhança do escritor que precisa desaparecer para criar, como se morresse um

\footnotetext{
${ }^{2}$ KANT, I. Segundo Livro: Analítica do Sublime In Crítica da Faculdade do Juízo. 2ª . Ed. Rio de Janeiro: Forense Universitária, 2010. p. 104.

${ }^{3}$ BLANCHOT, M. A obra e o espaço da morte in O espaço Literário. São Paulo: Rocco, 1987. pp. 83 - 159.
} 
pouco, o artista se sente atraído pelo desastre porque este o anula, faz com que desapareça. A visão do portentoso o fascinaria a ponto de se sobrepor à consciência de si mesmo. A experiência proporcionada pela realização de Homenagem a JMW Turner se alinha a essa característica de rasura do artista durante o processo de criação. Blanchot explica que ao criar o artista não é senhor de sua obra, antes permanece procurando uma direção que lhe escapa, de modo que o escritor se veria diante de uma reversão: daquele que dispõe da ação, que exerce um trabalho sobre a obra, àquele que percebe que a obra passa a ser aquilo que não possui relação alguma consigo, e que é precisamente desaparecendo, apagando-se que poderá criar. Outro aspecto que é necessário considerar consiste no fato de que tal rasura não ocorre, nesse caso, mediante a construção de um artefato grandioso ou mesmo a edificação de um monumento, mas mediante a destruição da matéria, no esplendor e dispêndio das chamas, bem como do gesto mesmo. A destruição, no entanto, edifica algo, pois transforma a matéria no inapreensível.

\section{Incorpóreo e infrangível}

Outra potência relacionada à paisagem que é recorrente na produção de Thiago Rocha Pitta se refere ao caráter infrangível encontrado no incorpóreo. Em uma exposição realizada no ano de 2009 na Meyer Riegger Gallery, situada na cidade alemã Karlsruhe, foram apresentados vários trabalhos em que o artista abordou brumas e névoas através de diferentes métodos e materiais. A obra que nomeava a exposição, The Rocky Mist ${ }^{4}$, é composta por quatro painéis de vidro fixados em um recipiente de quatro metros quadrados contendo salmoura, sendo que também sobre as placas de vidro o artista aplicou a solução, delineando um desenho semelhante a um perfil montanhoso. Com o tempo os cristais de sal se tornaram mais espessos e ultrapassaram a linha determinada anteriormente. As placas são de diferentes tamanhos e são dispostas paralelamente, sendo que a não coincidência do modo como estão posicionadas cria a sensação de espessura e densidade, como camadas translúcidas que se sobrepõem propiciando a sensação ora de proximidade, ora de distância, conforme a parcela de camadas sobrepostas

\footnotetext{
${ }^{4}$ No ano seguinte, na exposição Paralela 2010, realizada galpões do Liceu de Artes e Ofícios em São Paulo simultaneamente à Bienal de São Paulo, o mesmo trabalho foi exposto com o nome de Bruma Rochosa.
} 
que o olhar abarcar. O desenho branco dos pequenos cristais impregnando o vidro além de evocar a bruma, também se assemelha a silhuetas montanhosas e paisagens polares. Da maneira como explica o erudito francês de origem chinesa, François Cheng, se considerada pela ótica da pintura de paisagem chinesa, tal ambigüidade seria concebida como inerente a esses vapores, uma vez que são tidos como o vazio que suscita a transformação interna dos elementos da paisagem: Como se formam do vapor d'água e tem a forma dos montes, a nuvem e a bruma, em um quadro dão a impressão de produzir as duas entidades que são a água e a montanha no dinâmico processo de devir recíproco ${ }^{5}$. Essa transformação constante entre os dois pólos da paisagem chinesa, intermediada pelos vapores, se baseia na cosmologia taoísta, segundo a qual a noção de água-montanha está ligada ao par yin-yang: os dois sopros vitais complementares que regeriam, mediante sua interação, todos os seres.

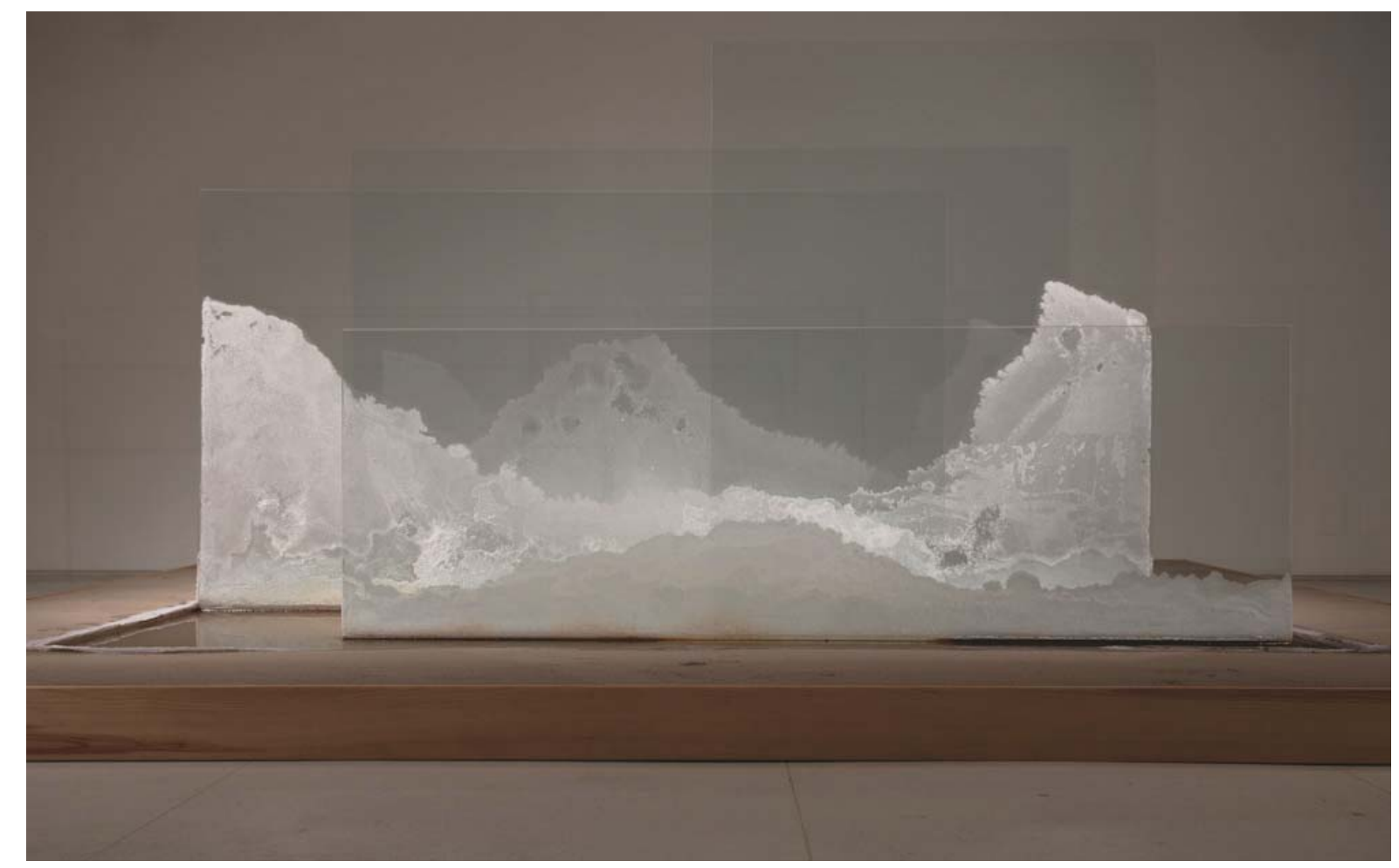

Thiago Rocha Pitta. Bruma Rochosa. Cristais de sal sobre vidro sobre água salgada. Dimensões variáveis, 2009. Galeria Millan, SP.

\footnotetext{
${ }^{5}$ CHENG, F. Vacio y Plenitud: el lenguage de la pintura china. Madrid: Siruela, 5a. ed. 2012. p. 193.
} 
Thiago Rocha Pitta empregara procedimento semelhante em uma obra que, além de integrar a exposição The Rocky Mist na galeria alemã, fora também exposta no ano anterior na mostra individual denominada Calmaria, na Galeria Milan, em São Paulo. Nuvem de cristais de sal era também composta por sal, porém apresentava dimensões mais modestas. Com o maior lado medindo 107 centímetros, a obra compreendia uma caixa de madeira disposta verticalmente, pendurada à parede como um quadro, em cujo interior, ao fundo, havia um papel com manchas decorrentes de aquecimento, como que queimado. Separado cerca de 10 centímetros do papel, um vidro era o que encobria a caixa, sendo que na parte superior do vidro se viam cristais de sal agregados. O título, Nuvem de cristais de sal, parecia sugerir uma paisagem em que as manchas na parte inferior do papel representariam terra, enquanto as nuvens de sal pairariam na parte de cima. No entanto, a materialidade do sal projetava uma sombra sobre o papel, de modo que se poderia supor uma vista aérea, assim, todo o papel seria o cenário árido encoberto parcialmente por nuvens.

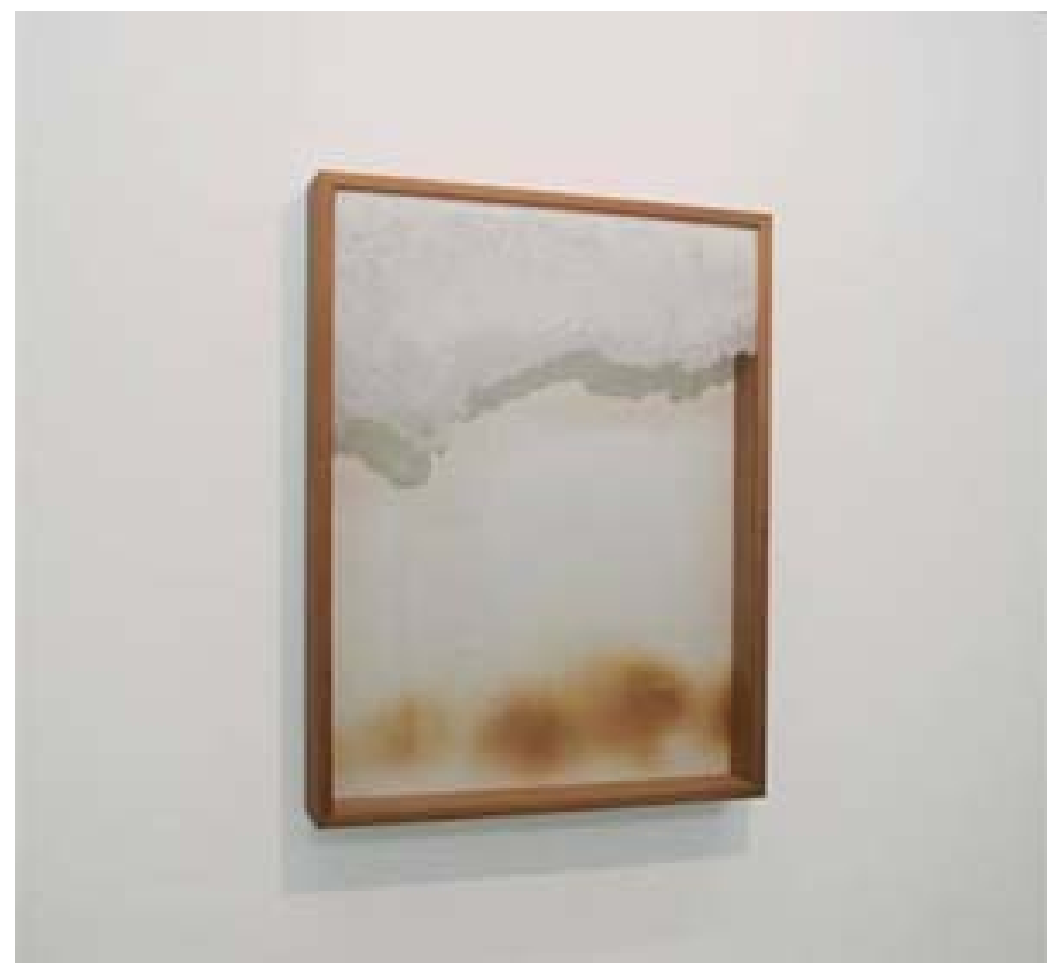

Thiago Rocha Pitta. Nuvem de cristais de sal. 
Se os dois trabalhos se aproximam pelo emprego do sal no vidro, produzindo um efeito de similitude entre cristais sólidos e vapores que se adensam e se esvaem rapidamente, o caráter escultórico da Bruma Rochosa permitia que o espectador vivenciasse a obra de maneira ambiental, circulando em volta do trabalho ${ }^{6} \mathrm{e}$ experimentando a possibilidade de se aproximar de uma névoa que não o envolve e nem se dissipa conforme a diminuição da distância. Esse aspecto não poderia ser contemplado por Bird in the fog $^{7}$, uma das aquarelas presentes na exposição The Rocky Mist. Nesse trabalho o artista se ocupou de apreender com tinta e pincel a matéria vaporosa que flerta com o incorpóreo. Os vários tons de cinza, em gradação delicada figuram o que parece ser uma paisagem marítima, em que o que sobressai é a atmosfera vaporosa. A paisagem oscila entre a opacidade e a translucidez: as nuvens, na parte superior, sugerem alguma profundidade por meio da gradação de cinzas em que os tons mais escuros se aproximam, e os mais claros conferem distância; já a parte central da imagem é dominada por um branco acinzentado bastante luminoso como vapores muito densos que impossibilitam enxergar adiante.

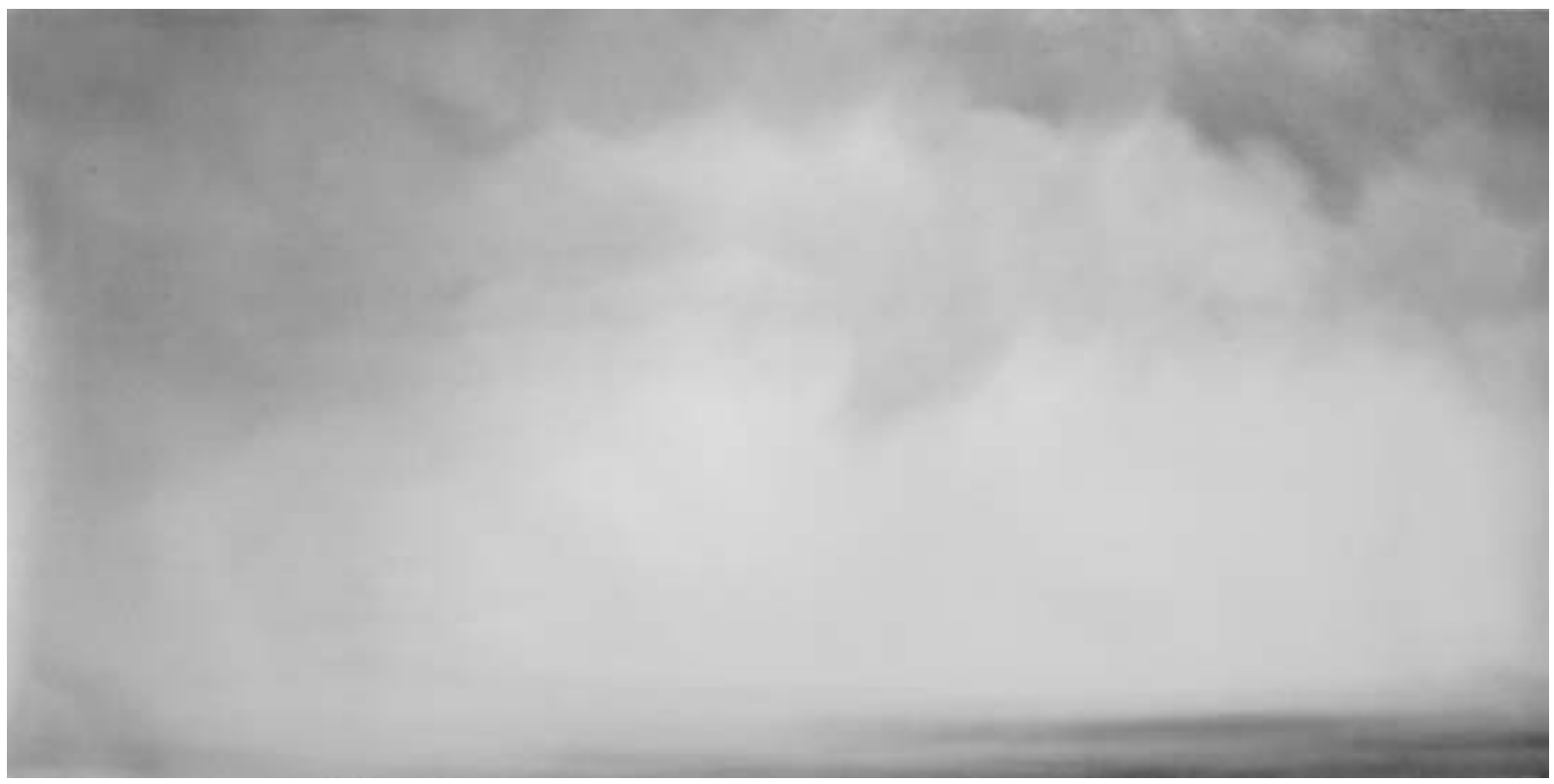

Thiago Rocha Pitta. O pássaro na névoa. Aquarela sobre papel. 113 × 224 cm. 2009 .

\footnotetext{
${ }^{6}$ Conforme é possível ver pelos registros fotográficos, é provável esse aspecto ambiental da obra tenha sido mais favorecido pelo modo como foi disposta na exposição Paralela 2010 em São Paulo, do que na galeria alemã em 2009, uma vez que na exposição mais recente ela foi posicionada no centro da sala de exposição com amplo espaço em volta, o que não ocorreu na mostra mais antiga.
}

${ }^{7}$ Pássaro na névoa seria o correspondente em português. 
Pode-se ver nos três trabalhos de que vimos falando um pensamento pictórico que inquire os fenômenos atmosféricos: Como pintar e retratar vapores? De que modo se pode evocar a fugacidade dessa matéria que se transforma continuamente, que apesar da fluidez pode se aglomerar, projetar sombras, velar objetos e espaços, e atenuar cores? Por meios diferentes e empregando materiais e técnicas distintas, o artista continua perguntando pictoricamente. Arrebatado pelo desastre sem medidas em que a destruição edifica a impressão do infinito no espírito, ou tocado pelos vapores infrangíveis, vemos nesses trabalhos de Thiago Rocha Pitta o esforço que se lança à tarefa incessante e incontornável de tangenciar a visibilidade da paisagem. 